\title{
ALUNOS COM NECESSIDADES EDUCACIONAIS ESPECIAIS NAS ESCOLAS REGULARES DE MOSSORÓ-RN
}

M. F. L. CHAGAS ${ }^{{ }^{*}}$ e F. K. D. DIAS ${ }^{2}$
Universidade Federal Rural do Semi-Árido - UFERSA
${ }^{1}$ Instituto Federal do Rio Grande do Norte - IFRN
fatima.aee@gmail.com*

\section{RESUMO}

Entende-se por educação especial, a modalidade de ensino, oferecida preferencialmente na rede regular de ensino, para educandos com NEE (necessidades educacionais especiais), a partir da educação infantil. Esse é um estudo descritivo e prospectivo, que analisou as concepções de 20 professores da educação infantil da rede regular de ensino da cidade de Mossoró-RN, que atendem alunos com NEE, sobre a educação inclusiva, sendo 10 professores da rede pública e 10 da rede privada. $O$ estudo propôs análises e reflexões sobre a educação inclusiva, seus conceitos e necessidades para a efetivação. As principais dificuldades indicadas pelos professores sobre a realização da inclusão apontaram para a falta de experiência e de formação profissional, número de alunos por sala de aula, apoio da família e infraestrutura de trabalho. Como sugestões de ações para garantir melhorias da qualidade do ensino se destacaram: mais cursos de formação continuada; infraestrutura adequada; trabalho em conjunto: escola/família/sociedade e a implementação de mais ações governamentais para esse propósito.

PALAVRAS-CHAVE: educação inclusiva, professor, ensino.

\section{STUDENTS WITH SPECIAL EDUCATIONAL NEEDS IN SCHOOLS REGULAR MOSSORÓ-RN}

\begin{abstract}
Is defined as special education, the type of education offered preferably in the regular education for students with SEN (special educational needs), from early childhood education. This is a prospective descriptive study, which examined the views of 20 teachers of early childhood education from the regular schools of the city of Mossoró-RN, serving students with special educational needs on inclusive education, 10 public school teachers and 10 private network. The study proposed analysis and reflections on inclusive education, their concepts and
\end{abstract}

needs in order to. The main difficulties indicated by the teachers on the implementation of the inclusion pointed to the lack of experience and training, number of students per classroom, family support and infrastructure work. As suggestions for action to ensure improvement of educational quality stood out: more continuing education courses, adequate infrastructure, work together: school / family / society and implementation of more government action for that purpose.

KEYWORDS: inclusive education, teacher, teaching. 


\section{INTRODUÇÃO}

Historicamente a escola passou por um período que se delimitava a poucos, pois era um privilégio de um pequeno grupo social. Durante muito tempo, este acesso permaneceu dificultado por diversas barreiras, uma delas era a deficiência, onde se observou a influência de um modelo médico acerca do conceito de deficiência (KASSAR, apud PINTO \& GÓES 2006), o qual se relacionava a uma condição orgânica de natureza incapacitante.

Tendo em vista a democratização escolar, a mesma passou a criar um paradoxo de inclusão e exclusão uma vez que universalizou o ensino, mas criou barreiras para os grupos e indivíduos considerados fora dos "padrões" do processo de ensino aprendizagem, realizando seleções de acesso e operando na regulação e produção das desigualdades. Essa problematização explicita os processos normativos de distinção dos alunos em razão de características intelectuais, físicas, culturais, sociais e linguísticas, entre outras estruturantes do chamado modelo tradicional de educação escolar. No entanto, a oportunidade de convívio com pessoas que não apresentam deficiência(s) torna possível uma vida de normalidade para aquele que tem algum tipo de deficiência, que através da socialização pode se perceber como uma pessoa capaz de se desenvolver em todos os aspectos (SOUZA, SOUZA \& SOUZA, 2007).

É indiscutível que quanto mais cedo se estabelecer a inclusão, melhor e mais fácil será para as crianças com ou sem deficiência experimentar positivamente essa convivência (SANTOS, OLIVEIRA \& LIMA, 2006).

Contudo, surge a problemática: que visão a escola e os professores tem acerca da educação inclusiva? Como acontece esse atendimento nas unidades de educação infantil? Há estrutura e recursos necessários ao atendimento de crianças com necessidades educacionais especiais?

Nesse sentido, as hipóteses que se apresentam, como o atendimento educacional especializado de qualidade nas escolas da educação básica, além da formação adequada para os professores, com vista a contribuir para uma prática profissional mais segura e condizente com as necessidades de cada criança, faz-se necessário pensar em intervenções que proporcionem à criança realizar seu desenvolvimento escolar/cognitivo, objetivando uma atuação no mundo de forma singular e criativa, possibilitando a emergência de sua subjetividade (PAULON, 2005).

Nessa perspectiva, é papel da escola participar da ampliação e enriquecimento do espaço potencial, oferecendo material cultural de modo que o aluno possa se apropriar dele de forma criativa e singular, preservando sua identidade pessoal e grupal (PAULON, 2005).

Diante das dificuldades de atendimento especializado no contexto socioeducativo dessas crianças surgiu a necessidade de investigar as concepções do corpo docente que trabalha diretamente com alunos que apresentam NEE (necessidades educacionais especializadas), para uma melhor adaptação do meio educacional, favorecendo a inclusão no processo de ensinoaprendizagem na rede básica de ensino, em especial no ensino infantil (de 0 a 6 anos) no município de Mossoró/RN. 


\section{EDUCAÇÃO E INCLUSÃO: PERCURSOS INVESTIGATIVOS}

Para o desenvolvimento desse trabalho investigativo, foi necessário um embasamento teórico, considerando O Estatuto da Criança e do Adolescente - ECA, Lei no 8.069/90, que no artigo 55, determina que "os pais ou responsáveis têm a obrigação de matricular seus filhos ou pupilos na rede regular de ensino". Tendo em vista também que existe a necessidade de prestar assistência às pessoas com deficiência para que elas possam desenvolver suas habilidades nos mais variados campos de atividades e para promover sua integração à vida normal; a Lei de Diretrizes e Bases da educação nacional (LDB), a lei $n^{\circ} 9394$ de 20 de dezembro de 1996, que fala da educação especial como modalidade de educação escolar, sendo ofertada preferencialmente em rede regular de ensino, começando desde o ensino infantil (0 a 6 anos); o Decreto $n$ ㅇ 3.298, que regulamenta a Lei no 7.853/89, ao dispor sobre a Política Nacional para a Inclusão da Pessoa com Deficiência, onde define a educação especial como uma modalidade transversal a todos os níveis e modalidades de ensino, enfatizando a atuação complementar da educação especial ao ensino regular; a Declaração de Salamanca, (UNESCO, 1994), onde estabelece a inclusão enfatizando que:

[...]as escolas devem acolher todas as crianças, indepentemente de suas condições físicas, intelectuais, sociais, mocionais, linguísticas ou outras. Devem acolher crianças com deficiência e crianças bem-dotadas; crianças que vivem nas ruas e que trabalham; crianças de populações distantes ou nômades; crianças de minorias linguísticas, étnicas ou culturais e crianças de outros grupos ou zonas desfavorecidos ou marginalizados (Decla ração de Salamanca, 1994, p. 18).

Outros teóricos como STAINBACK (2006), PAULON, (2005), MENDONÇA (2010) e outros citados nas referências bibliográficas, contribuíram com seus estudos e pesquisas sobre a educação inclusiva, formação continuada e recursos materiais necessários à inclusão de alunos com NEE na educação básica regular.

\section{EXPERIÊNCIA COM EDUCADORES DE ESCOLAS PÚBLICAS E PRIVADAS}

Este estudo descritivo e prospectivo foi baseado nas respostas e nas experiências relatadas de 20 professores do gênero feminino da rede básica de ensino infantil, no ano de 2011, sendo 10 da rede pública e 10 da rede privada, que tem em seu cotidiano escolar, alunos com necessidades cognitivas especiais. Foram feitas entrevistas com 11 questões de múltipla escolha e descritivas a fim de avaliar o grau de conhecimento do docente em promover o processo de ensinoaprendizagem dos educandos com algum tipo de deficiência, precisando assim de um atendimento educacional especializado. Nesse sentido, serão utilizados critérios que foram julgados importantes, como: sexo, tempo de atuação em magistério, tempo de atuação em educação especial e participação em eventos, focalizando as concepções sobre a Educação Inclusiva como conceitos, ideias e opiniões que relatadas e descritas por profissionais da área.

Nas entrevistas semiestruturadas, foram inclusos temas que abordaram as dificuldades encontradas pelos participantes na realização do processo ensino-aprendizagem e condições necessárias à efetivação da Educação Inclusiva, além de sugestões dos docentes quanto aos aspectos necessários para a viabilização da inclusão escolar, bem como o conhecimento sobre as leis e diretrizes que regem a educação especial no Brasil. As entrevistas foram aplicadas no intervalo das aulas nas respectivas escolas selecionadas, nos horários matutinos e vespertinos. A 
estatística utilizada foi descritiva através da frequência relativa às quais serão apresentadas em gráficos percentuais.

\section{COMPREENDENDO RESULTADOS}

Dos vinte professores participantes, observarmos o tempo de atuação profissional no magistério e na educação especial, criando faixas anuais de 1-5 anos, 6-10 anos, 11-15 anos, 16-20 anos, 21 anos ou mais, distribuídos no gráfico 01 que mostra o tempo de atuação no magistério tanto na rede pública quanto na rede privada de ensino regular.

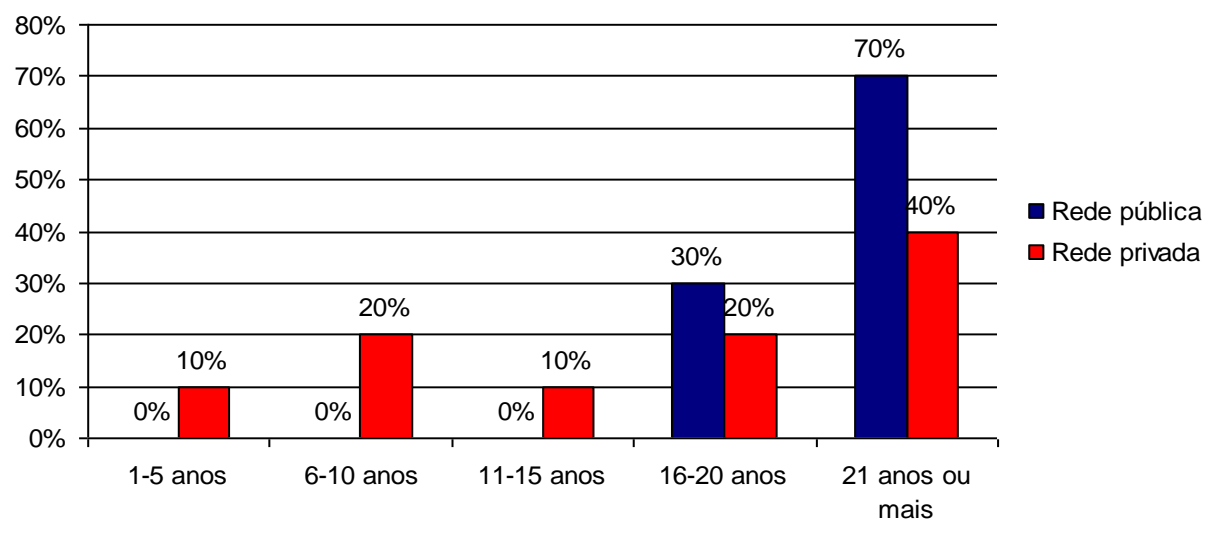

Gráfico 01: Tempo de atuação no magistério, dos professores da rede regular de ensino de Mossoró-RN

Em relação ao tempo de atuação em educação especial, temos o gráfico 02 que expressa o tempo dos professores da rede pública e os professores da rede privada de acordo com a faixa anual estabelecida.

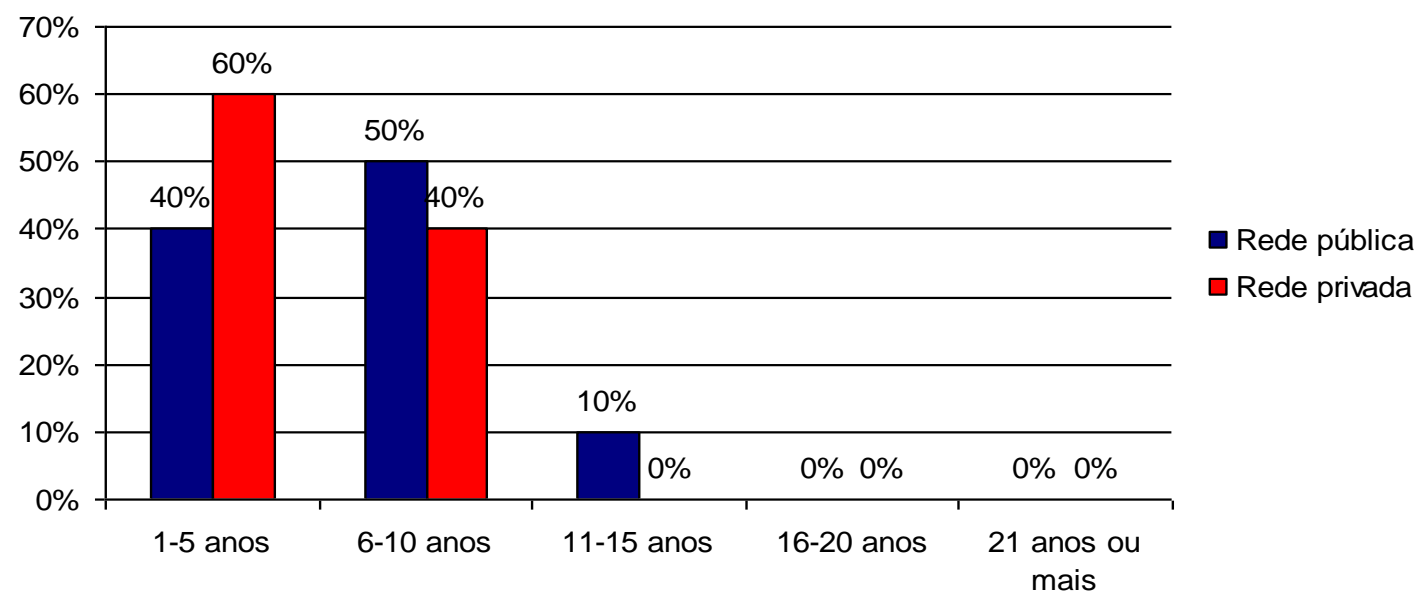

Gráfico 02: Tempo de atuação em educação especial, dos professores da rede regular de ensino de Mossoró-RN

Nos gráficos 01 e 02, pode-se observar que os professores da rede pública de ensino que foram entrevistados possuem maior tempo de atuação profissional no magistério e também na educação especial se compararmos com os professores entrevistados da rede privada. Percebeuse que apesar do tempo de atuação em escola regular ser bastante considerável e existir certo 
tempo de atuação em educação especial entre os professores entrevistados, o nível de formação e de experiência com a inclusão ainda foi um problema bastante enfatizado por ambas as redes.

Ao perguntar se os profissionais tinham alguma experiência prévia antes de entrar na educação especial, todos responderam que não. Para que o professor tenha sucesso dentro de uma sala de aula heterogênea é necessária uma preparação prévia, sendo o trabalho focalizado tanto com a turma toda quanto com os alunos de forma individual, como mostra o estudo realizado por NASCIMENTO (2008) onde é enfatizado que os professores realizadores de trabalhos bem sucedidos na educação inclusiva possuem outras habilidades adquiridas no decorrer da sua prática que os ajudam a envolver a classe como, por exemplo, estabelecer bons relacionamentos que satisfaçam as necessidades psicológicas básicas dos alunos. Essas habilidades não nascem com os bons professores, mas são adquiridas através da capacitação adequada dos mesmos.

Os dados confirmam que a experiência do tempo de serviço na rede regular nem sempre é suficiente para dar suporte às necessidades na educação especializada, uma vez que a criança com NEE (necessidades educacionais especiais) possui formas específicas de aprendizagem, onde se deve buscar um maior aprofundamento nas metodologias de ensino.

Segundo a Declaração de Salamanca (UNESCO, 1994), a preparação adequada de todo pessoal da educação constitui um fator-chave na promoção do progresso em direção às escolas inclusivas.

Quanto à participação em cursos de capacitação e eventos na área de educação especial nos últimos cinco anos, apenas três professoras da rede pública de ensino responderam que tinham participado de cursos na área e duas professoras da rede pública de ensino participaram de eventos voltados à educação especial, como congressistas. Sabe-se que o sistema de ensino deve assegurar aos educandos com necessidades educacionais especiais, currículos, métodos, técnicas, recursos educativos e organização específica, para atender às suas necessidades específicas, bem como professores com especialização adequada em nível médio, superior e/ou em formação continuada para atendimento educacional especializado, capacitados para a inclusão desses educandos nas classes regulares de ensino (STAINBACK, 2006).

Ao perguntar se esses profissionais tinham recebido algum tipo de orientação antes de atuar como profissionais da educação especial, observamos que 7 professoras da rede pública responderam que receberam orientação de professores anteriores da criança, da própria escola e dos pais do aluno, mas não receberam informações especializadas, e todas as professoras da rede privada de ensino responderam que receberam orientações por parte da direção da escola (uma delas citou um evento promovido pela própria escola, com os professores, porém grifou como superficial), orientações com os pais da criança e antigos professores.

Segundo PAULON (2005), uma das dificuldades encontradas na formação dos educadores no estudo para o trabalho com alunos com necessidades educacionais especiais, existe um amplo leque de realidade cultural em nosso país. Para atender essa demanda tão diversa, o material dirigido à formação tem se proposto a oferecer uma linguagem suficientemente abrangente para ser acessível a todos. Porém, se observa a excessiva simplificação dos conteúdos propostos, gerando uma superficialidade que se distancia das reais situações.

Quanto a questão que se referia ao conceito de educação especial, foram coletas respostas como: "Uma educação desenvolvida para todos sem distinção"; "Uma educação onde os 
professores tenham que ter materiais disponíveis para atender as necessidades de cada um"; "Educação onde os profissionais estejam preparados para atender as crianças"; "Educação para todos onde a criança tem que estar matriculada em uma escola regular"; "Educação sem preconceitos".

De acordo com a LDB, os professores conseguiram conceituar educação especial, porém omitindo algumas informações importantes como a importância de começar esse ensino desde a educação infantil e se estender ao ensino superior e que esse tipo de educação é uma modalidade dentro do sistema educacional e não uma educação à parte.

No gráfico 03 foram relacionadas algumas dificuldades citadas pelos professores entrevistados, como a falta de experiência profissional na área de educação especial que foi apontada tanto pelas profissionais da rede pública como da rede privada como sendo uma das principais dificuldades no que se refere ao atendimento adequado dessas crianças no processo de ensino-aprendizagem.

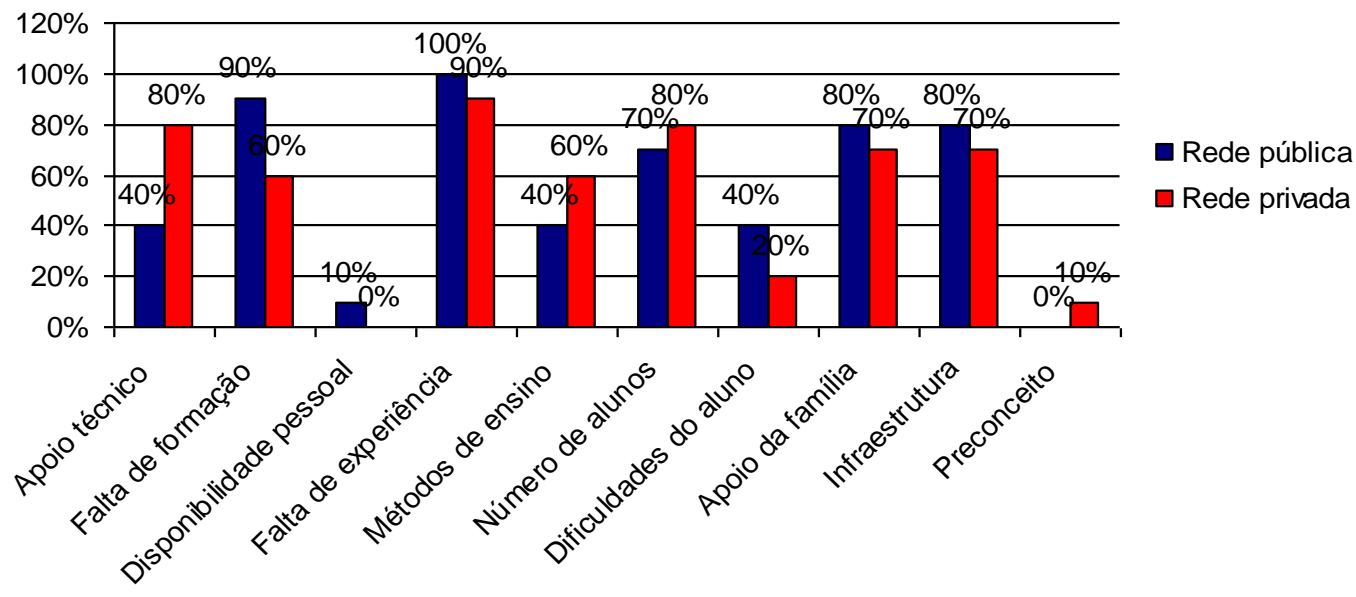

Gráfico 03: Dificuldades enfrentadas em educação especial pelas professoras da rede básica de ensino de Mossoró-RN

Observou-se também nesse gráfico que o apoio técnico foi citado como outra dificuldade da rede privada bem mais até que na rede pública demonstrando que nem sempre o maior poder aquisitivo gera mais benefícios e investimentos, tendo em vista que muitas escolas privadas veem a educação de forma capitalista, isto é, como mercadoria, isso muitas vezes inviabiliza a contratação de profissionais para o apoio técnico no âmbito escolar.

Mesmo que o apoio técnico especializado esteja previsto na LDB, como uma alternativa complementar ao processo de ensino dessas crianças, em muitas escolas essa alternativa não existe e nem tem perspectiva de existência em curto prazo. PAULON (2005) esclarece que a interação entre profissionais, como por exemplo, da saúde, especializados em atender crianças com deficiência(s) e os profissionais da educação é fundamental para o processo de ensino aprendizagem dos mesmos.

Outro problema gerado pelo sistema capitalista na rede privada de ensino, bastante comentado pelos professores é o número de alunos por sala de aula, várias escolas da rede privada superlotam as salas de aulas, diminuindo as possibilidades de trabalhar com os alunos de forma individualizada, considerando as especificidades de cada um individualmente e coletivamente. MENDONÇA (2010) cita que a superlotação das salas de aula impede a individuação dos alunos e 
interferem na qualidade da aquisição da leitura e escrita, tais como a inadequação de métodos específicos às particularidades dos educandos.

$\mathrm{Na}$ rede pública de ensino, as dificuldades citadas com mais ênfase foram: falta de formação, de experiência e infraestrutura que, segundo os entrevistados, mostram a não existência de um sistema de condições mínimas para a inclusão. PAULON (2005), em seu estudo sobre análises de referenciais da educação especial explicou que a formação profissional é crucial na melhoria do processo de ensino e enfrentamento das diferentes situações que implica na tarefa de educar. Muitas vezes essa formação mínima impede que o profissional crie condições de ensino, tendo em vista os recursos que são disponibilizados na escola e o fato de não saber manipulá-los.

Em ambas as escolas o apoio familiar foi citado como um fator de entrave no processo de ensino-aprendizagem em educação especial, pois os pais tendem a responsabilizar à escola pela educação total da criança, outras vezes superprotegem e negam a frequência e assiduidade dos filhos na escola, muitas vezes por não acreditar nas potencialidades e capacidades de aprendizagem do filho ou por motivos de indisponibilidade de tempo, sendo o trabalho fora de casa um dos principais argumentos que impedem o acompanhamento escolar.

LOPES \& MARQUEZAN (2009) relata em seus estudos a importância da família como principal responsável pelas ações do filho com necessidades cognitivas especiais. Segundo esses autores, é a família que lhe oferece a primeira formação. Logo, é imprescindível o seu papel no acompanhamento educacional da criança que apresente algum tipo de deficiência.

Para STAINBACK (2006), apesar de todos os esforços feitos na educação dessas crianças, o foco maior deve ser em ajudá-los a dominar e usar as suas habilidades como meio de aprendizagem e não como um fim. É importante lembrar que o desenvolvimento de habilidades especiais de comunicação e percepção são necessárias para que seja garantido sucesso na atuação em sociedade. Alguns instrumentos como jogos educativos e interativos de computadores, Karaokê entre outros ajudam no desenvolvimento percepto-cognitivo dessas crianças, ampliando assim as possibilidades de aprendizagem.

Diante das dificuldades mencionadas anteriormente, os professores sugeriram algumas ações voltadas à educação especial que possibilitariam melhorias na qualidade do ensino especial na rede regular de ensino, como mostra o gráfico 04 :

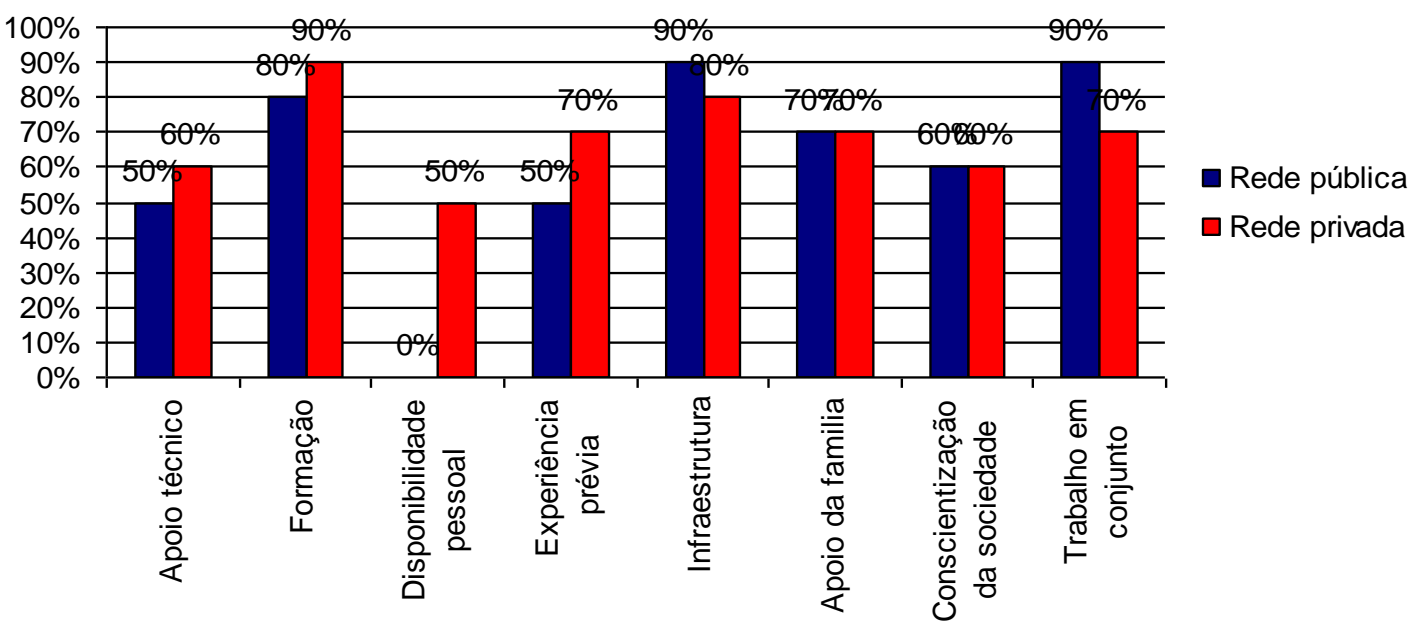

Gráfico 04: Ações que geram melhorias em educação especial sugeridas pelas professoras da rede básica de ensino de Mossoró-RN. 
Os fatores apontados como importante para o estudo foram o trabalho em conjunto e a conscientização da sociedade como ações propiciadoras de melhoria na qualidade do ensino especializado. As ações em conjunto são importantes para o processo de ensino-aprendizagem, bem como a integralização da criança no meio social. Talvez um professor sozinho não consiga abarcar toda a bagagem de conhecimentos necessários para alcançar os objetivos necessários, porém a constituição de uma equipe interdisciplinar, que permita pensar o trabalho educativo nos diversos campos do conhecimento, é fundamental para compor uma prática inclusiva junto aos professores, trabalhando em conjunto, como disse PAULON (2005), em seu documento subsidiário à política de inclusão.

Nessa conjuntura, a sociedade tem um papel crucial na formação, concretização e valorização de um ser apto realizar atividades, independente de suas dificuldades, oferecendo formas de acessos à educação, saúde, esportes, lazer e cultura. "É somente por meio de um esforço coletivo que o compromisso com o núcleo de valores sociais, de justiça, de tolerância, de interesse e respeito pelo outro pode ser adquirido" (STAINBACK, 2006).

\section{CONSIDERAÇÕES FINAIS}

O estudo apresentou resultados que permitiu refletir sobre as concepções dos professores a respeito das questões que tem dificultado a inclusão das crianças com necessidades cognitivas especiais no sistema regular de ensino. Os professores demonstraram acreditar na eficiência da educação especial, mas para que isso aconteça afirmaram a necessidade de uma mudança no sistema educacional de ensino onde devem ser levadas em consideração ações necessárias para que o processo aconteça de forma contínua.

Os professores estão conscientes de não estarem preparados para a inclusão e por isso justificam que precisariam de apoio técnico especializado, dos familiares e da sociedade para proporcionar as crianças um ensino adequado às suas necessidades específicas. Pode-se perceber que as dificuldades são semelhantes, não havendo, portanto grandes diferenças entre as classes econômicas, quando comparamos as redes públicas e privadas. Essas dificuldades não são exclusividade do ensino especial, mas esses problemas de atendimento com qualidade existem há várias décadas na estrutura educacional do país.

É perceptível nas escolas de educação básico, um desprepara formativo e uma estrutura ineficiente para formar o desenvolvimento pleno dos cidadãos como rege a Constituição Federal. Os dados obtidos vêm reafirmar essa afirmação.

Apesar de leis e documentos garantindo a inclusão, o direito de acesso e permanência na rede regular de ensino a todos os cidadãos, o que está claro, através de pesquisas, é que a preocupação em formular a teoria não tem acompanhado as ações práticas governamentais para efetivar essas garantias, tendo em vista que os profissionais da educação não têm um programa de formação continuada na área inclusiva e as escolas não oferecem estrutura física adequada e nem apoio técnico especializado para esse atendimento.

Conclui-se com a realização desse estudo que para desenvolver um trabalho inclusivo nas escolas de ensino infantil, há uma urgente necessidade de transformações particulares e coletivas, visando uma reforma considerável na estrutura da escola comum e na formação continuada dos 
professores, visando combater atitudes discriminatórias e assim proporcionar uma educação mais efetiva e com mais qualidade a todas as crianças envolvidas no processo de ensino e aprendizagem.

\section{REFERÊNCIAS BIBLIOGRÁFICAS}

1. BARROS, A. Alunos com deficiência nas escolas regulares: limites de um discurso. Revista Saúde e sociedade, Salvador, v.14, n. 13, p. 119-133, Set-Dez 2005.

2. DECLARAÇÃO DE SALAMANCA. Salamanca: UNESCO, 1994. 17 p.

3. DUTRA, C. P. et al. Política Nacional de educação especial na perspectiva da educação inclusiva. Revista MEC/SEESP,Brasília,p.1,2007.

4. ELIAS, M.P. et al. Acessibilidade a benefícios legais disponíveis no Rio de Janeiro para portadores de deficiência física. Revista Ciência e saúde Coletiva, Rio de Janeiro, v.13, n. 3, p. 1041-1050, Set. 2007.

5. FÁVERO, O. et al. Tornar a educação inclusiva.2. ed. Brasília: UNESCO, 2009.

6. JURDI, A. P. S.; AMIRALIAN, M. L. T. M. A inclusão escolar de alunos com deficiência mental: uma proposta de intervenção do terapeuta ocupacional no cotidiano escolar. Revista Estudos de Psicologia, Campinas, v.23, n.2, p.191-202. Jun.2006.

7. LOPES, R.P.V.; MARQUEZAN, R.O envolvimento da família no processo de integração/inclusão do aluno com necessidades especiais. Revista eletrônica pedagogo Brasil, fev.2010. Disponível em: http://www.pedagobrasil.com.br/educacaoespecial/ oenvolvimentodafamilia.html Acesso em 03 de mar. 2011.

8. MENDONÇA, A. Andreia Mendonça defende o número de alunos na sala de aula. Bahia press, Salvador, 06 abr.2010. Col. Educação.

9. NASCIMENTO, A.T.C.B., Liga Portuguesa dos Deficientes Motores: de Instituição de Educação Especial e Reabilitação a Centro de Recursos; de Centro de Recursos a Fundação: Estudo de caso de uma organização, 2008, 658 f. Tese (Doutorado em estudos da criança: área da educação)-Instituto de estudos da criança, Universidade do Minho, Braga, Portugal, 2008.

10. NUNES, C.C. \& Aielo, A.L.E. Interação entre irmãos: deficiência mental, idade e apoio social da família. Revista Psicologia: reflexão e crítica, São Carlos, v.21, n. 1, p. 42-50, Jun. 2007.

11. PADILHA, A.M.L. Práticas educativas: Perspectivas que se abre para a educação especial. Revista Educação \& Sociedade, Franca, Ano XXI, n 71, p.197-219, Jul. 2000.

12. PAULON, S.M. Educação Inclusiva: documento subsidiário à política de inclusão.1. ed. Brasília: MEC/SEE,2005.

13. PINTO, G.U. GÓES, M.C.R. Deficiência mental, imaginação e mediação social: um estudo sobre o brincar. Revista Brasileira de Educação Especial, Marília, v. 12, n. 01, p. 11-28, Jan. - Abr 2006.

14. PLAISANCE, Eric; Denominações da infância: do anormal ao deficiente. Revista Educação e sociedade, Campinas, v. 26, n. 19, p. 405-417, 2005.

15. QUINTÃO, D.T.R. Algumas reflexões sobre a pessoa portadora de deficiência e sua relação com o social. Revista Psicologia \& Sociedade, Canoas, v. 17, n 01, p. 17-28, Jan. - Abr. 2005.

16. ROSIN-PINOLA, A.R. DEL PRETTE, Z. A. P. DEL PRETTE, A. Habilidades sociais e problemas de comportamento de alunos com deficiência mental, alto e baixo desempenho acadêmico. 
Revista Brasileira de Educação Especial, Marília, v.13, n. 02, p. 239-256, mai/Ago 2007.

17. SANT'ANA,I. M. Educação Inclusiva: concepções de professores e diretores. Revista psicologia em estudo, Maringá, v.10, n.2, p.227-234, 2005.

18. SANTOS, F; OLIVEIRA, F.F; LIMA, R.A expectativa dos alunos do curso de educação física em relação às pessoas portadoras de necessidades especiais. In: XI CONGRESSO CIÊNCIAS DO DESPORTO E EDUCAÇÃO FÍSICA DOS PAÍSES DE LÍNGUA PORTUGUESA DA USP, 2006, São Paulo. Anais eletrônicos. São Paulo: USP, 2006. Disponível em: www.usp.br/eef/xipalops2006/61_Anais_p221.pdf. Acesso em: 17 set.2011.

19. SILVA, S.C; ARANHA, M.S.F. Interação entre professor e alunos em sala de aula com proposta pedagógica de educação inclusiva. Revista Brasileira de educação especial, Marília,v.11,n.3,p.373-394,2005.

20. SILVA, N. L. P; DESSEN, M.A. Deficiência Mental e Família: Implicações para o Desenvolvimento da Criança. Revista Psicologia: Teoria e Pesquisa, Brasília, v.17, n. 2, pp.133-141, Mai-Ago 2001.

21. Deficiência Mental e Família: Uma análise da produção científica. Revista Paidéia-FFCLRP-USP, Ribeirão Preto, p.12-23, Ago-Dez 2000.

22. SOUZA, H.C.D.; SOUZA, J.L.;SOUZA,M.M.A.O construtivismo discutindo os alunos portadores de deficiência mental grau leve, 2007, 25 f. Monografia (Especialização em Educação inclusiva) - Universidade Salgado de Oliveira, São Gonçalo, RJ, 2007.

23. STAMATO, J.M.A.; VIANA, V. A. Z. Formação de professores e educação inclusiva: uma experiência com caso de ensino. Revista eletrônica da Faculdades Integradas de BebedouroFAFIBE, São Paulo,Fev.2010. Disponível em: www.fafibe.br/.../059-jucelia_vivianeformacao_professores_educ_incl.pdf Acesso em 15 de mar. De 2011.

24. STAINBACK, S. Considerações contextuais e sistemas para a educação inclusiva. Revista Inclusão. Brasília, Ano 2, n.3, p.8-14, 2006.

25. SUGESTÕES E ESTRATÉGIAS PARA UMA PRÁTICA INCLUSIVISTA. Brasilia: Revista Inclusão, 50p.

26. SÚMULA: POLÍTICA NACIONAL DE EDUCAÇÃO ESPECIAL NA PERSPECTIVA DA EDUCAÇÃO INCLUSIVA. Campinas: Caderno Cedes, 2008.5p. 